\title{
Reform of Vocal Music Singing Teaching Mode Based on Musical
}

\section{Performance}

\author{
Tingting Chen ${ }^{1, a}$ \\ ${ }^{1}$ Normal College, Nanyang Institute of Science and Technology, Nanyang City, Henan Province, \\ 473000, China \\ ${ }^{\mathrm{a} e m a i l}$
}

Keywords: Vocal music singing; Teaching mode; Reform; Musical

\begin{abstract}
The musical is a collection of music, dancing, singing, acting and other art forms as one of the stage art. At the same time, because of its strong inclusiveness, art forms are also rich and diverse. In the teaching of vocal music, musical has been the concern of educators as a more complete type of music. At the same time, the vocal music teaching with the musical has made some progress, which also makes educators gradually realize the importance of musicals in the teaching of art and vocal music. Based on the author's learning and teaching experience, this paper first analyzed the application status of the musicals in vocal music teaching, and then discussed the necessity of the application of musicals in vocal music teaching. Finally, it put forward the reform and innovation of the teaching methods of vocal music singing.
\end{abstract}

\section{Introduction}

With the more and more rich social and cultural life, the unique charm of musicals has been continuously accepted by the audience. Musicals originally originated in the West and had a long history of development. Musicals are enduring classics whatever the one of Britain's four major plays Cat or The Phantom of the Opera. However, as far as the artistic form is concerned, musical combines traditional and modern singing methods and the traditional and modern forms of dance are absorbed in the artistic performance. In the stage art, the modern lighting effect with audio equipment and so on are integrated into it. It can be said that the musical has a strong inclusive, thus becoming one of the more powerful music performing art form the world stage. The Western musical history in China can be traced back into the last century in 1980s. With the spread of musicals in China, many local musicals have appeared and become more and more popular among the public. Musicals are rich and diverse in both musical style and musical forms. Therefore, it has a very important reference significance for modern vocal music teaching.

\section{Application Status of the Musicals in Vocal Music Teaching}

Compared with the West, practice and experience of application status of the Chinese musicals in vocal music teaching is not perfect. The time of musical entering its application in vocal music teaching is not mature with short time in China, and there is a problem of low normative and random. Specifically, on the one hand, in the process of musical performance, the basic elements of vocal music, such as tone, timbre and melody can not be standardized. This leads to the result that 
whole musical is not harmonious and the artistic effect is greatly reduced. On the other hand, the musical has comprehensive features with more diverse music style, which makes the vocal music teaching difficult to standardize. Secondly, the general law of vocal music performance is from simple to complex, from easy to difficult, vocal trainers need to gradually find their own conditions of vocal ways. In the process of vocal music teaching, the arbitrariness of musicals makes the performance loose and breaks the general rules of vocal music performance that students have recognized. Because many teachers lack experience in the integration of vocal music and musical drama, they will have some influence on the artistic style and emotional expression of the whole musical.

\section{Necessity of Application of the Musicals in Vocal Music Teaching}

Perfect the teaching contents. There are two aspects that musical perfects the vocal music teaching. The first is the vocal music teaching level. The traditional vocal music teaching pays more attention to the teaching of music theory, but less to professional vocal music practice training. This will not only lead to slow progress of students' professional level, but also make the content of vocal music teaching rigid. The traditional vocal music teaching practice is mainly regarding the common and popular with three great ways of singing as guidance contents. The type of music in musical contains is very rich, which can improve the vocal music teaching content and has promoting effect on it. The second is the vocal music level. The traditional vocal music teaching requires students to master the singing skills of each kind of singing methods and strengthen the practice of singing methods, which is difficult. The diversity of music styles and types requires students to strengthen all kinds of basic vocal exercises. Therefore, the way of musical training for students can let them to practice on different tracks and improve the ability of vocal singing.

Enhance integrative quality of students. In the process of teaching vocal music, the introduction of musical is to help the students to learn daily theory, such as Aesthetics and Outline of Dramatic Art. They are presented through script writing and acting. This can promote students' performance ability, emotional aesthetic ability and musical ability, which also has a positive impact on the creation of recreation for their artistic works. The traditional vocal music teaching focuses on the acquisition of vocal elements. With the increasingly high demands on the aesthetic, artistic performance is more vital than before. The musical combines singing and body movements to provide emotional support for singing. Therefore, in the vocal music teaching process, the solid vocal music performance is the foundation. Moreover, the practice for musical performances needs to be measurable. In the process of vocal music teaching, because of the different quality of students, the ability to master the emotion of vocal music will also be different. Musical combines the songs with the situation and the stage effect to present and contrast the emotions in the play. Therefore, it is very important for performers to quickly integrate into the scene and express their emotions effectively. It would be useful to enhance musical performances on students' sense of music. The "sound" provides service to "love", so the sound strength, gas conversion, real audio sound, vibrato, mute use will affect the expression of a whole song. As a result of this, compared to the traditional teaching of vocal music, musical and teaching are more helpful to improve the overall quality of students, so as to achieve the goal of teaching benefits teachers as well as students.

Highlight the artistic value of musical. The artistic value contained in musical is various. In macroscopic view, from the theoretical level of vocal music teaching, and from the practical level of vocal music teaching to teaching means, almost all the vocal music teaching activities can not work 
without the guidance of musical. Because of this, artistic value of musical was really prominent. First of all, musical in vocal music teaching help to emphasize music singing in musicals. The fusion of vocal music teaching to musical, mines diverse musical type, style and singing methods with instructive value. Secondly, the vocal music teaching in the musical can emphasize musical characteristics of dance performances. Vocal music teaching pays attention to the singing wonderfully with a silver voice and deep feeling. The dance performance in musical has important practical significance to guide students' physical performance. The vocal music teaching in the musical stresses the core role of musical. Vocal music teaching can enable students to consciously add dramatic elements in the interpretation of related tracks, and make the works deep, artistic and concise, so that to promote the complete performance of the works. Therefore, the reference from various aspects that the vocal music teaching brought to the musical is the affirmation of musical art value.

\section{The Reform and Innovation of Vocal Music Singing Teaching Method in Musical}

Perfect the original vocal music teaching mode from the singing foundation of musical. In the process of vocal music teaching, any kind of singing methods have their own unique singing skills. From the musical point of view, the main point of singing is pitch singing. In the future teaching, vocal music educators should focus on the skills course of the pitch singing. Before contacting the vocal music singing in musical, educators should give the students a good command of the singing method of "chest voice". Here are some simple explanations. "Chest voice singing" refers to the chest resonance. Educators should carry out the singing training based on pitch in the classroom, so that learners can use the real voice to perform the singing training in the middle and low voice area. First of all, the educator should let learners practice the correct use of breath, so that to help them to master the correct breath adjustment skills. In the process of training, we want to support the breath down to the location of the lower abdomen with the waist to form a ring state. We must carefully feel the breath that can surround whole body, and then use the strength of the diaphragm to breath into the body of middle abdomen. We should pay attention to using the power of lower abdomen to continuously aspirated. Secondly, educators should also teach students the question about how to master the harmony between pitch and breath. In the training process, learners should make their vocal cords remain in all in a state of shock, and use the strength of the lower abdomen to support the transmission of breath. What we should pay attention to here is that the learners should make sure that the larynx is as large as possible. Only by improving the flexibility of your voice, can the singing voice be more vigorous rather than weak when singing.

Enrich students' musical singing style, and enhance vocal singing skills. In the course of vocal music singing teaching, educators should let the students contact with different types of music singing style as many as possible,so that to broaden their horizons and improve their singing level. Bel canto is a common singing method in musical performance, and it is an important basic learning content in the teaching of vocal singing. However, in the past teaching, many educators focus too much on the bel canto of the professor, but neglect the contacting with other types of music style, so that performances become nothing new without musical beauty. Based on this, the vocal music educators in the development of basic training of bel canto, will appropriately add some of the more popular music singing elements. In addition, because the musical in the performance of the process has a high ornamental and entertainment, educators should incorporate some popular elements compared with popular taste in the day after the training in singing. They should have some 
innovative style and elements on the basis of bel canto, and grasp the various singing style between conversion. Remember that adverse effects may not be superfluous and curry favour by claptrap.

\section{Summary}

To sum up, due to the current vocal music singing teaching in China being still in the learning stage, educators should try to use a variety of different types of vocal methods to carry out vocal training for students. It is precisely that the musical singing is not limited to any kind of singing methods. Thus, it has the unique charm that other music art forms can not match. The author believes that in the near future, China will also be able to cultivate more high-quality musical talent, in the international stage.

\section{References}

[1] Cao Yihuan, Zhang Xiaoqing. Research on Chinese Musical in Vocal Music Teaching in Normal University[J]. Voice of the Yellow River, 2017, (14): 31-32.

[2] Du Jiayao. Enlightenment of Singing Characteristics of Musicals to Traditional Vocal Music Teaching[J]. Theatre House, 2016, (17): 27-28.

[3] Kang Xiaodan. Research on the Singing Teaching Mode of Musicals[J]. Drama House, 2016, (08): 189-190.

[4] Wu Shanshan. Research on the Teaching Mode Reform of Vocal Music Singing[J]. Music Space and Time, 2016, (04): 166-167.

[5] Xu Hanmei. A Preliminary Study of Musical Singing in Concert[J]. Voice of the Yellow River, 2012, (13): 110-111.

[6] Wang Wei. Singing Style and Method of Musical[J]. Journal of Jilin College of the Arts, 2012, (03): 2-4.

[7] Tu Jinying. Research on Vocal musical Teaching Reform[J]. Art Education, 2012, (05): 40-41. 